\title{
Tratamento conjugado de lixiviado de aterro sanitário e esgoto doméstico por processo anaeróbio seguido de aeróbio
}

\section{Treatment conjugate of landfill leachate and domestic wastewater by anaerobic process followed by aerobic}

Data de entrada: 29/01/2014

- Data de aprovação: $14 / 11 / 2014$

Risoneide Borges da Silva / Valderi Duarte Leite

DOI:10.4322/dae.2014.143

\section{Resumo:}

O objetivo desta pesquisa foi investigar o processo de tratamento conjugado de lixiviado de aterro sanitário e esgoto doméstico em reator UASB seguido de filtro aeróbio percolador. O sistema adotado visou a tratar lixiviado de aterro sanitário combinando-o com esgoto doméstico, proporcionando condições de tratamento favoráveis para obter um efluente que atenda aos padrões de descarte em corpos receptores. 0 sistema experimental era constituído de um reator UASB seguido de um filtro aeróbio percolador e demais dispositivos complementares. Os reatores eram alimentados com substrato constituído por $99 \%$ de esgoto doméstico mais $1 \%$ de lixiviado de aterro sanitário (percentagem em volume) e o processo de monitoramento foi realizado em duas diferentes etapas. Na etapa 1, as eficiências médias de remoção de DBO5 do reator UASB, filtro aeróbio e sistema foram, respectivamente, $48 \%, 34 \%$ e $60 \%$ e, na etapa 2, 63\%, 36\% e $76 \%$, sendo DQO total de $60 \%, 60 \%$ e $85 \%$ (etapa 1) e $70 \%, 62 \%$ e $89 \%$ (etapa 2 ).

Palavras-chave: Lixiviado de aterro sanitário. Reator UASB. Filtro aeróbio percolador.

\section{Abstract:}

The objective of this research was to investigate the treatment process combined landfill leachate and domestic sewage in UASB reactor followed by aerobic trickling filter. The system adopted aimed to treat landfill leachate combining it with sewage, providing conditions favorable treatment to obtain an effluent that meets the standards for discharge into receiving bodies.The experimental system consisted of a UASB reactor followed by an aerobic trickling filter and additional devices. The reactors were fed with substrate consisting of $99 \%$ of domestic sewage plus $1 \%$ of landfill leachate (volume percent) and the monitoring process was carried out in two different steps. In step 1, the average removal efficiencies of BOD5 of the UASB reactor, aerobic filter and the system was respectively $48 \%, 34 \%$ and $60 \%$ and in the second stage $63 \%, 36 \%$ and $76 \%$. And COD Total $60 \%, 60 \%$ and $85 \%$ (step 1), and $70 \%, 62 \%$ and $89 \%$ (step 2).

Keywords: Sanitary landfill leachate. UASB reactor. Aerobic trickling filter.

Risoneide Borges da Silva

Licenciada em Química e mestre em Ciência e Tecnologia Ambiental pela Universidade Estadual da Paraíba (UEPB).

\section{Valderi Duarte Leite}

Engenheiro químico e mestre em Engenharia Civil com concentração em saneamento ambiental pela Universidade Federal da Paraíba (UFPB), Doutor em Hidráulica e Saneamento pela Escola de Engenharia de São Carlos da Universidade de São Paulo (EESC/USP). Professor da UEPB.

\section{Endereço para correspondência:}

Rua S. R. Fundo S/N, S. S. de Lagoa de Roça

CEP 58119-000 Paraíba - Brasil

Telefone: (83) 9988-0355

E-mail: risobrgsquiahotmail.com 


\section{INTRODUÇÃO}

Nos últimos anos, a quantidade, o volume e a composição dos resíduos sólidos urbanos têm alterado bastante; isso se deve, principalmente, ao aumento populacional, às mudanças nos estilos de vida das pessoas e ao desenvolvimento e consumo de produtos que são menos biodegradáveis (ASASE et al., 2009).

Segundo dados da Pesquisa Nacional de Saneamento Básico (PNSB) de 2008, realizada pelo Instituto Brasileiro de Geografia e Estatística (IBGE, 2010 a), no Brasil são coletadas diariamente cerca de 260 mil toneladas de Resíduos Sólidos Urbanos (RSUs), sendo que 50,8\% têm como destinação lixões, $22,5 \%$, aterros controlados e $27,7 \%$, aterros sanitários.

No Brasil, atualmente ainda é muito utilizado o aterro sanitário para destinação final dos resíduos sólidos, causando grandes impactos ambientais, desde a sua construção até sua operação e após seu encerramento (SANTOS; JORDÃO, 2012).

A utilização de aterros sanitários gera ampla discussão acerca dos subprodutos gerados: lixiviado e biogás. Segundo Oman e Junestedt (2008), o lixiviado contém compostos de natureza orgânica e nitrogenada, dos quais muitos podem causar problemas à saúde pública e ao meio ambiente se lançados sem tratamento na natureza. Para Renou et al. (2008), para satisfazer as condições de lançamento do lixiviado nos corpos receptores, se faz necessário tratamento adequado, que pode ser físico, químico ou biológico, bem como a combinações de todos.

Os principais processos de tratamento biológico podem ser compostos de processo aeróbio, como lodo ativado e filtros aeróbios, e processo anaeróbio, como reator anaeróbio de fluxo ascendente (reator UASB) e filtros anaeróbios (BOHDZIEWICZ; KWARCIAK, 2008).

O sistema de tratamento anaeróbio é um processo de degradação microbiológica de multietapa, compreendendo a hidrólise, acidogênese, acetogênese e metanogênese (NGES; LIU, 2009). Nesse processo, a matéria orgânica é convertida em uma forma mais oxidada ( $\mathrm{CO}_{2}$ ) e em uma forma mais reduzida $(\mathrm{CH} 4)$. Isso ocorre devido à interação de diferentes tipos de microrganismo.

O tratamento aeróbio utiliza oxigênio para converter a matéria orgânica em produtos inertes (CO2), transformando cerca de $40 \%$ a $50 \%$ da matéria orgânica que alimenta o sistema.

Segundo Renou et al. (2008), há poucos anos, o tratamento combinado de lixiviado e esgoto doméstico em estações de tratamento de esgoto era uma solução comum para o tratamento de lixiviados, haja vista a fácil manutenção e os baixos custos operacionais.

Portanto, o objetivo principal deste trabalho é analisar o desempenho do processo de tratamento biológico anaeróbio seguido de aeróbio de lixiviado de aterro sanitário e esgoto doméstico em duas diferentes situações operacionais.

\section{MATERIAIS E MÉTODOS}

O sistema experimental foi projetado, construído e monitorado nas dependências físicas do Laboratório da Estação Experimental de Tratamentos Biológicos de Esgotos Sanitários (Extrabes) da Universidade Estadual da Paraíba, localizada na cidade de Campina Grande-PB.

O substrato consistiu da mistura de $99 \%$ de esgoto doméstico mais $1 \%$ de lixiviado de aterro sanitário (percentagem em volume), tendo sido preparado diariamente e submetido à caracterização química com frequência semanal.

O esgoto doméstico utilizado na sua preparação foi coletado do sistema de esgotamento sanitário da cidade de Campina Grande - PB, tomado de um de seus interceptores (interceptor Leste), que passa dentro das dependências da Extrabes. 
O lixiviado utilizado para preparação do substrato foi coletado no aterro sanitário da cidade de João Pessoa-PB, o qual recebe os resíduos do Consórcio de Desenvolvimento Intermunicipal da Região Metropolitana, constituído pelas cidades de Santa Rita, Bayeux, Cabedelo, Lucena, Conde, Cruz do Espírito Santo e João Pessoa.

O sistema experimental foi projetado em escala piloto, sendo constituído de um reservatório de polietileno de 250 litros para armazenamento do substrato, um reator UASB, um filtro aeróbio de leito percolador, uma bomba peristáltica e demais dispositivos complementares. 0 meio de suporte utilizado para recheio do filtro aeróbio percolador foi brita número 19 com volume de vazios de 47\%. Na Figura 1, apresenta-se o desenho esquemático do sistema experimental e, na Tabela 1, são apresentados os dados dos parâmetros físicos dos reatores.

O monitoramento do sistema experimental foi realizado durante o período de outubro de 2012 a julho de 2013. A operação foi dividida em duas diferentes etapas, a fim de avaliar a carga orgânica e a carga superficial aplicadas ao reator UASB
Tabela 1 - Parâmetros físicos e operacionais dos reatores.

\begin{tabular}{|c|c|c|}
\hline Característica & Reator UASB & Filtro aeróbio \\
\hline $\begin{array}{l}\text { Forma de } \\
\text { operação }\end{array}$ & Fluxo contínuo & Bateada \\
\hline Altura (m) & 2,37 & 2 \\
\hline Diâmetro (mm) & 150 & 150 \\
\hline Volume $\left(\mathrm{m}^{3}\right)$ & 0,045 & 0,035 \\
\hline $\begin{array}{r}\text { Substrato } \\
\text { utilizado }\end{array}$ & \multicolumn{2}{|c|}{$\begin{array}{c}\text { Esgoto doméstico (99\%) mais lixiviado } \\
\text { de aterro sanitário (1\%) }\end{array}$} \\
\hline
\end{tabular}

e ao filtro aeróbio com leito percolador, respectivamente, nas duas etapas. Para iniciar o monitoramento do experimento, foi adotada a Carga Orgânica Volumétrica (COV) de $1 \mathrm{kgDBO} 5 / \mathrm{m}^{3}$.dia para a primeira etapa e $1,5 \mathrm{kgDBO} 5 / \mathrm{m}^{3}$.dia para a segunda para o reator UASB.

$\mathrm{Na}$ Tabela 2, estão apresentados os parâmetros operacionais aplicados aos reatores nas duas etapas de monitoramento.

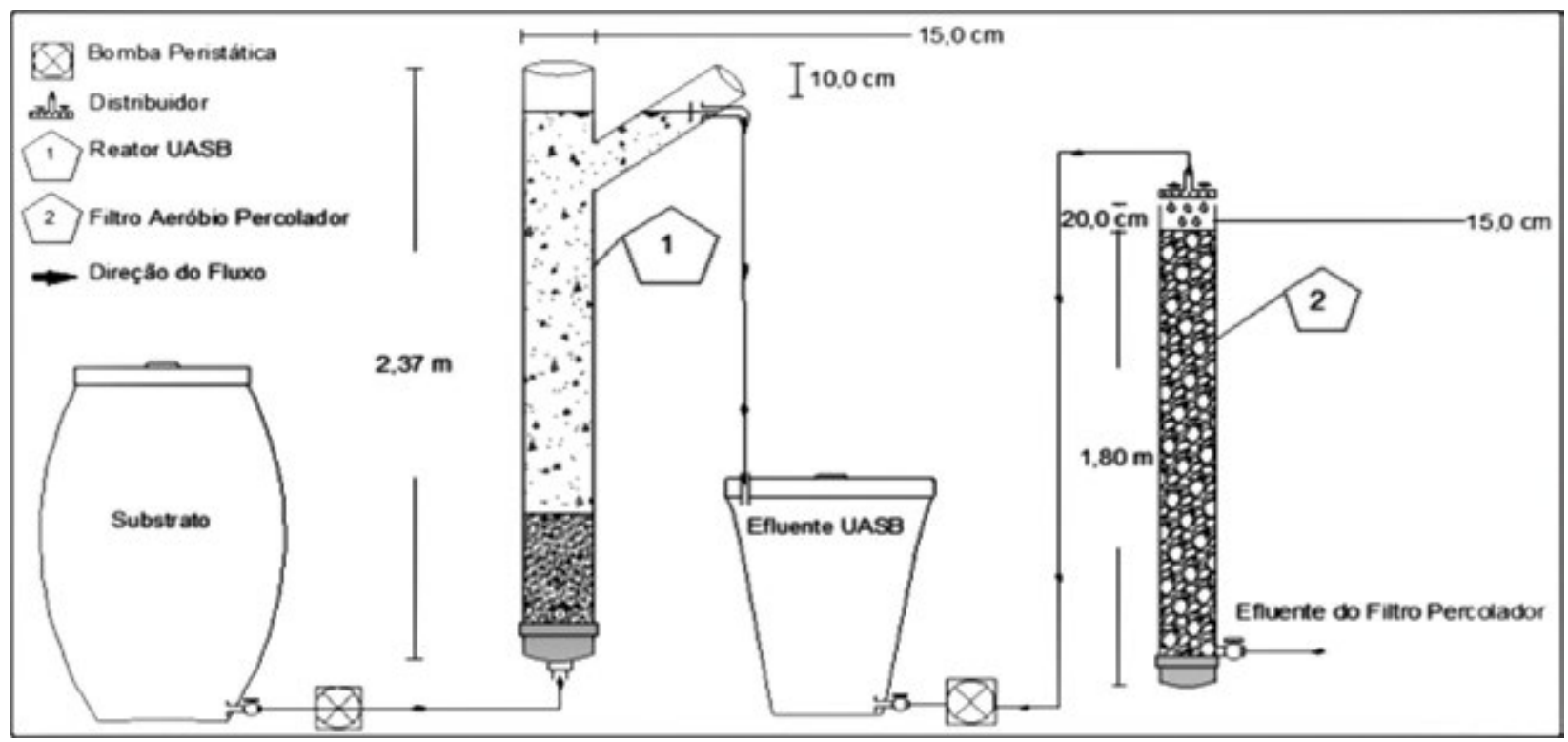

Figura 1 - Desenho esquemático do sistema experimental. 
Tabela 2 - Características operacionais dos reatores nas duas etapas de monitoramento dos reatores.

\begin{tabular}{|c|c|c|c|c|}
\hline \multirow[t]{2}{*}{ Característica } & \multicolumn{2}{|c|}{ Reator UASB } & \multicolumn{2}{|c|}{ Filtro aeróbio } \\
\hline & Etapa 1 & Etapa 2 & Etapa 1 & Etapa 2 \\
\hline Vazão afluente (L.dia-1) & 143 & 227 & 42 & 84 \\
\hline $\begin{array}{l}\text { Carga orgânica volumétrica } \\
\left(\mathrm{kgDBO} 5 / \mathrm{m}^{3} \text {.dia }\right)\end{array}$ & 1,0 & 1,5 & 0,4 & 0,6 \\
\hline $\begin{array}{l}\text { Carga hidráulica volumétrica } \\
\qquad\left(\mathrm{m}^{3} / \mathrm{m}^{3} . \text { dia }\right)\end{array}$ & 3,17 & 5,0 & 3 & 6,0 \\
\hline $\begin{array}{l}\text { Taxa de aplicação superficial } \\
\qquad\left(\mathrm{m}^{3} / \mathrm{m}^{2} . \mathrm{dia}\right)\end{array}$ & --- & -- & 2,39 & 4,7 \\
\hline $\begin{array}{l}\text { Tempo de detenção hidráulica } \\
\text { (horas) }\end{array}$ & 7,5 & 5,0 & --- & --- \\
\hline Tempo de enchimento & --- & --- & 30 minutos & 20 minutos \\
\hline Tempo de reação & --- & --- & 6,0 horas & 20 minutos \\
\hline Tempo de esvaziamento & --- & --- & 30 minutos & 20 minutos \\
\hline Tempo de repouso & --- & --- & 1,0 hora & 3,3 horas \\
\hline
\end{tabular}

As amostras do resíduo líquido do afluente e efluente dos reatores foram coletadas e analisadas semanalmente com métodos preconizados pela American Public Health Association (APHA, 2005).

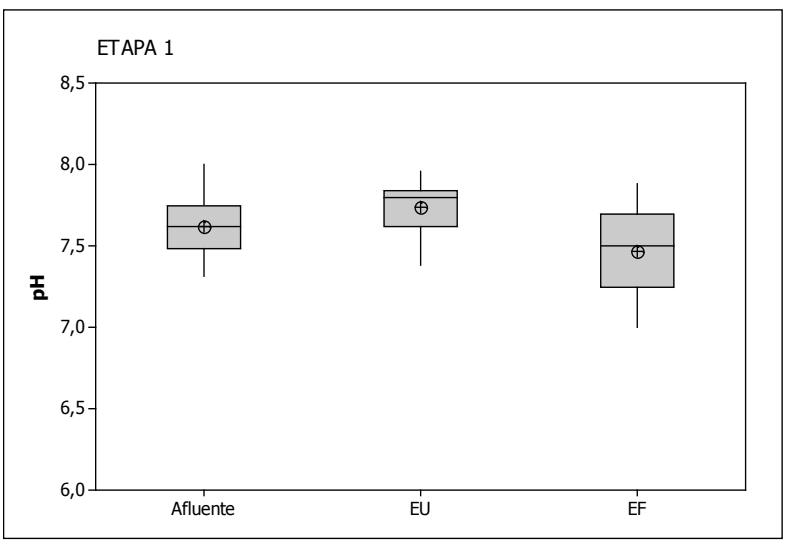

\section{RESULTADOS E DISCUSSÕES}

O comportamento das variações temporais do $\mathrm{pH}$ dos resíduos líquidos afluentes e efluentes ao longo do período de monitoramento do reator UASB e do filtro aeróbio de leito percolador, nas duas diferentes etapas do trabalho, é apresentado na Figura 2.

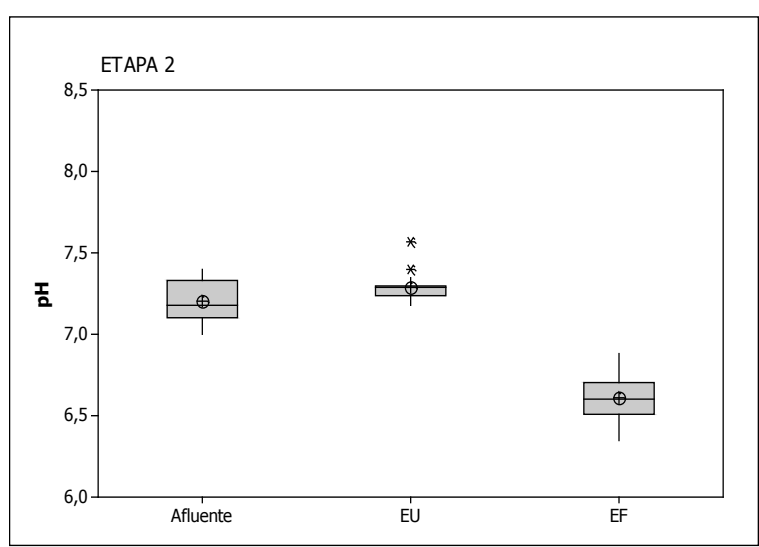

Figura 2 - Comportamento da variação temporal do pH dos resíduos líquidos nos processos anaeróbio e aeróbio. 
Analisando as magnitudes pontuais do $\mathrm{pH}$ do resíduo líquido (afluente) alimentado no reator UASB na primeira etapa, pode ser constatado que a variação foi de 7,3 a 8,0, com magnitude média de 7,5; na segunda etapa, a variação foi de 7,0 a 7,4, com magnitude média de 7,3. A variação da magnitude do $\mathrm{pH}$ no afluente pode estar associada prioritariamente ao lixiviado de aterro sanitário, devido ao fato de ele ter sido coletado no aterro sanitário com frequência mensal e armazenado por esse mesmo período, o que propiciou a elevação do $\mathrm{pH}$, frente à dinâmica bioquímica estabelecida pelas espécies nitrogenadas. No reator UASB, foi percebido um leve acréscimo na magnitude do $\mathrm{pH}$, haja vista não ter sido propiciado consumo de alcalinidade total. Na segunda etapa, não se observou variação

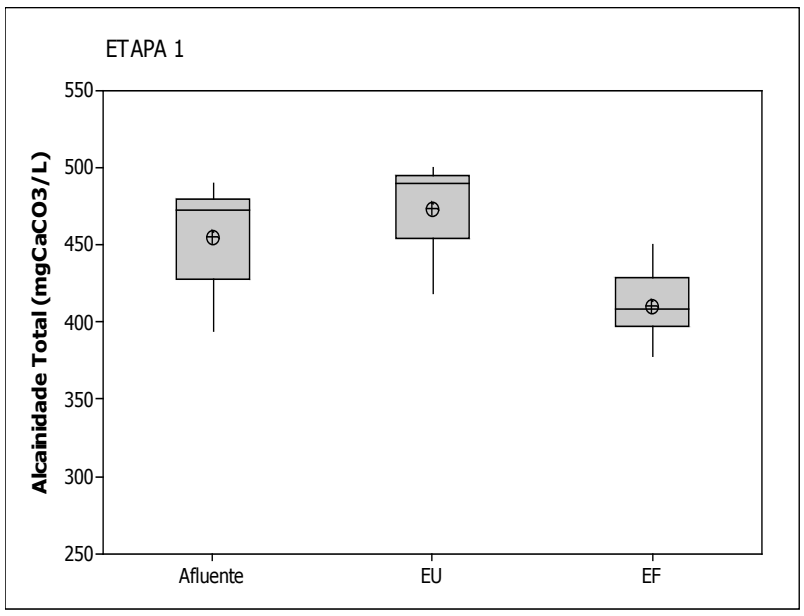

significativa na magnitude do $\mathrm{pH}$ do afluente nem do resíduo líquido efluente do reator UASB, mesmo considerando que, nessa etapa, a carga orgânica aplicada ao reator UASB foi $50 \%$ superior à carga orgânica aplicada na primeira etapa. No entanto, no filtro aeróbio com leito percolador, foi constatada redução significativa na magnitude do $\mathrm{pH}$ do resíduo líquido efluente. Nessa etapa, foi aumentado o tempo de repouso do filtro, aumentando significativamente o acúmulo de oxigênio no meio filtrante e, consequentemente, melhorando o processo de nitrificação.

A alcalinidade total do afluente apresentou uma concentração média na primeira etapa de 471 $\mathrm{mgCaCO}_{3} / \mathrm{L}$ e, na segunda etapa, $412 \mathrm{mgCaCO}_{3} / \mathrm{L}$ (Figura 3).

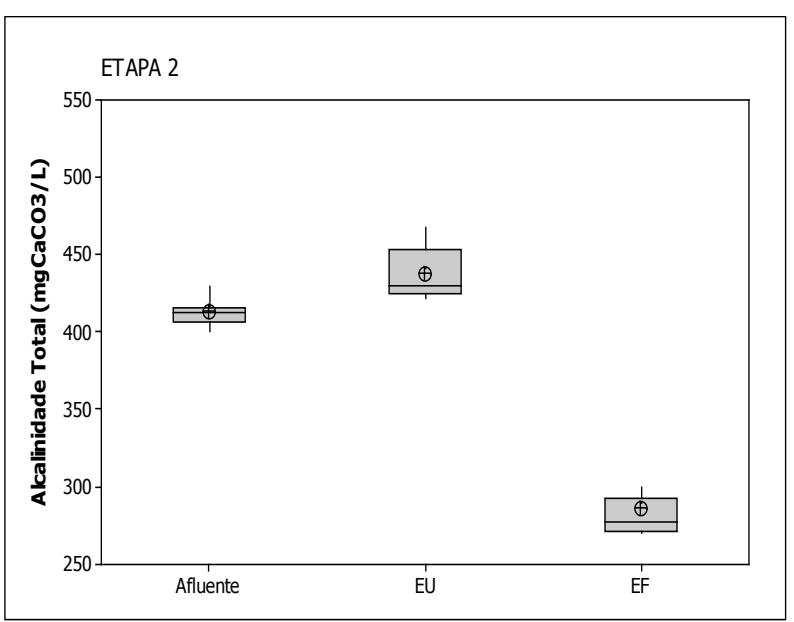

Figura 3 - Valores de alcalinidade total obtidos nas duas etapas de monitoramento dos reatores.

Constatou-se aumento da alcalinidade na fase anaeróbia, com concentração média do efluente do reator UASB de $472 \mathrm{mgCaCO}_{3} / \mathrm{L}$ (etapa 1) e $440 \mathrm{mgCaCO}_{3} / \mathrm{L}$ (etapa 2). Esse aumento de alcalinidade no reator anaeróbio deve-se ao processo de amonificação. Para Van Haandel e Lettinga (1994), no processo de digestão anaeróbia, a alcalinidade é gerada a partir da amonificação ou remoção dos Ácidos Graxos Voláteis (AGVs), garantindo a manutenção do valor do $\mathrm{pH}$ e a estabi- lidade do processo. No efluente do filtro aeróbio, é possível observar considerável diferença de alcalinidade total entre as duas etapas, tendo sido verificado um consumo de alcalinidade de $14 \%$ na primeira etapa, com concentração média de 407 $\mathrm{mgCaCO}_{3} / \mathrm{L}$, indicando baixo consumo, porque o processo de nitrificação foi mínimo. $\mathrm{Na}$ segunda etapa, o consumo foi de $35 \%$, com concentração média de $285 \mathrm{mgCaCO}_{3} / \mathrm{L}$, ocorrendo maior nitrificação e estabilização do sistema. 
Observa-se, na Figura 4, que a concentração de AGVs no efluente do reator UASB foi de $85 \mathrm{mgHA}-$ C/L na primeira etapa e de $77 \mathrm{mgHAc} / \mathrm{L}$ na segunda etapa, indicando, nessas condições, menor produção de AGVs em reatores UASB operando com maior carga orgânica. Os AGVs diminuíram do afluente para o efluente do reator UASB, evidenciando que está ocorrendo o consumo deste e a consequente conversão a metano. Pode-se constatar que a concentração média de AGV do afluente, na primeira etapa, foi de $111 \mathrm{mgHAc} / \mathrm{L}$ e do efluente final, $56 \mathrm{mgHAc/L}$, com eficiência média de redução de $49 \%$. Na segunda etapa, a concentração média do AGV foi de $109 \mathrm{mgHAc/L}$ para o afluente e $52 \mathrm{mgHAc} / \mathrm{L}$ para o efluente final, com eficiência média de redução de 53\%.
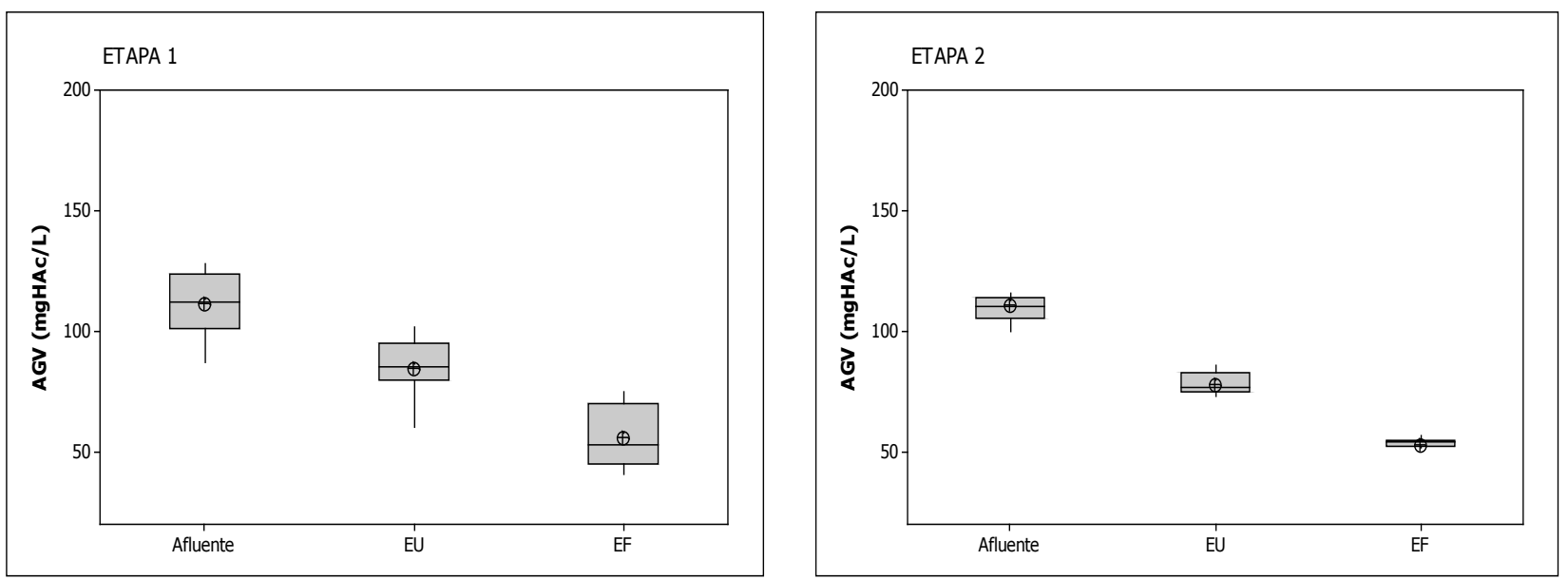

Figura 4 - Valores de AGV obtidos nas duas etapas de monitoramento dos reatores.

A concentração média de Demanda Bioquímica de Oxigênio (DBO5) do afluente foi de $265 \mathrm{mg} / \mathrm{L}$ na primeira etapa e $221 \mathrm{mg} / \mathrm{L}$ na segunda etapa. Os valores médios de DBO5 do efluente do reator UASB foram de $137 \mathrm{mg} / \mathrm{L}$ e $81 \mathrm{mg} / \mathrm{L}$ na primeira e segunda etapas, respectivamente, tendo o reator UASB eficiência média de remoção de $48 \%$ na etapa 1 e $63 \%$ na etapa 2 , constatando-se maior eficiência na segunda etapa, em que operou com COV de $1,5 \mathrm{kgDBO} 5 / \mathrm{m}^{3}$.dia. A concentração média de DBO5 do efluente final foi de $90 \mathrm{mg} / \mathrm{L}$ (primeira etapa) e $52 \mathrm{mg} / \mathrm{L}$ (segunda etapa), destacando-se eficiência total na remoção de DBO5 no sistema de $60 \%$ na primeira etapa e $76 \%$ na segunda etapa.
Na Figura 5, são apresentadas as concentrações de DBO5 em mgO2/L nas duas etapas de monitoramento do sistema experimental.

Observa-se que, nesse sistema experimental de reator UASB seguido de filtro aeróbio percolador, foi produzido um efluente final com concentrações médias de 90 e 52 mg/L, encontrando-se em ambas as etapas dentro dos padrões de descarte ambiental estabelecidos pela Resolução CONAMA 430/2011.

Quanto aos valores de Demanda Química de Oxigênio (DQO), observa-se na Figura 6 que a concentração de DQO total do afluente apresentou valores médios de $567 \mathrm{mg} / \mathrm{L}$ na primeira etapa e $552 \mathrm{mg} / \mathrm{L}$ na segunda etapa. 

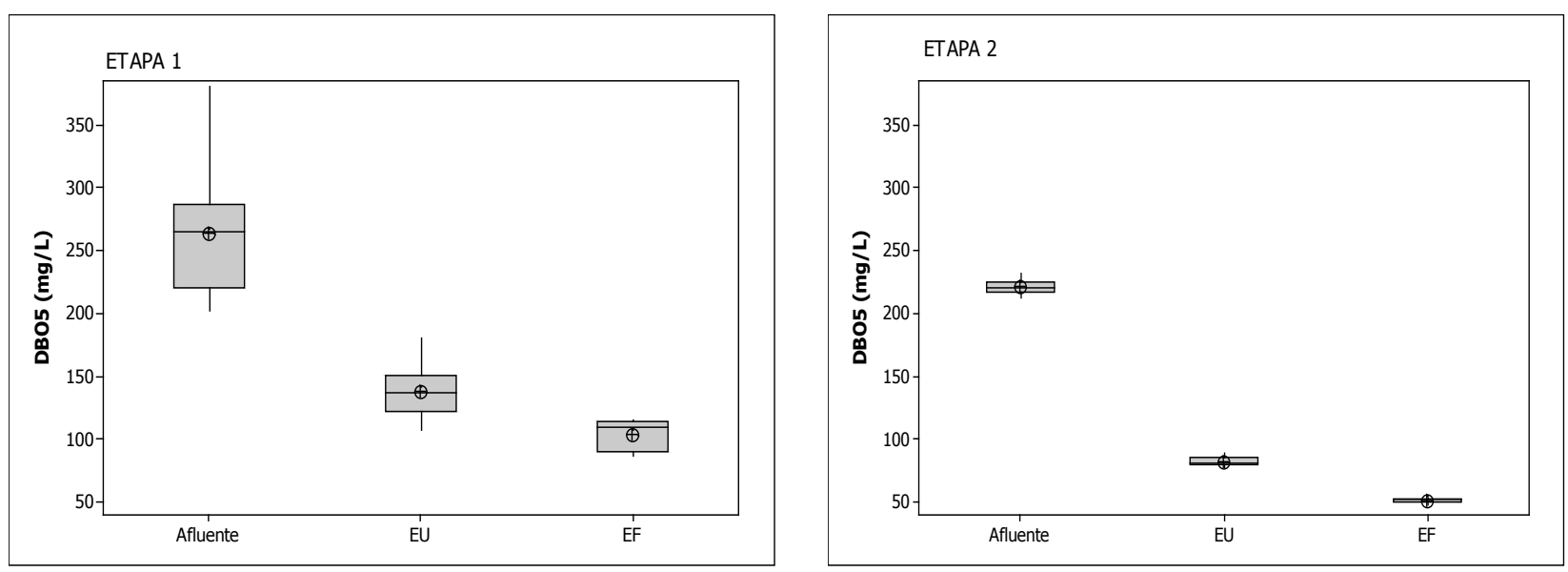

Figura 5 - Valores de DBO5 obtidos nas duas etapas de monitoramento dos reatores.
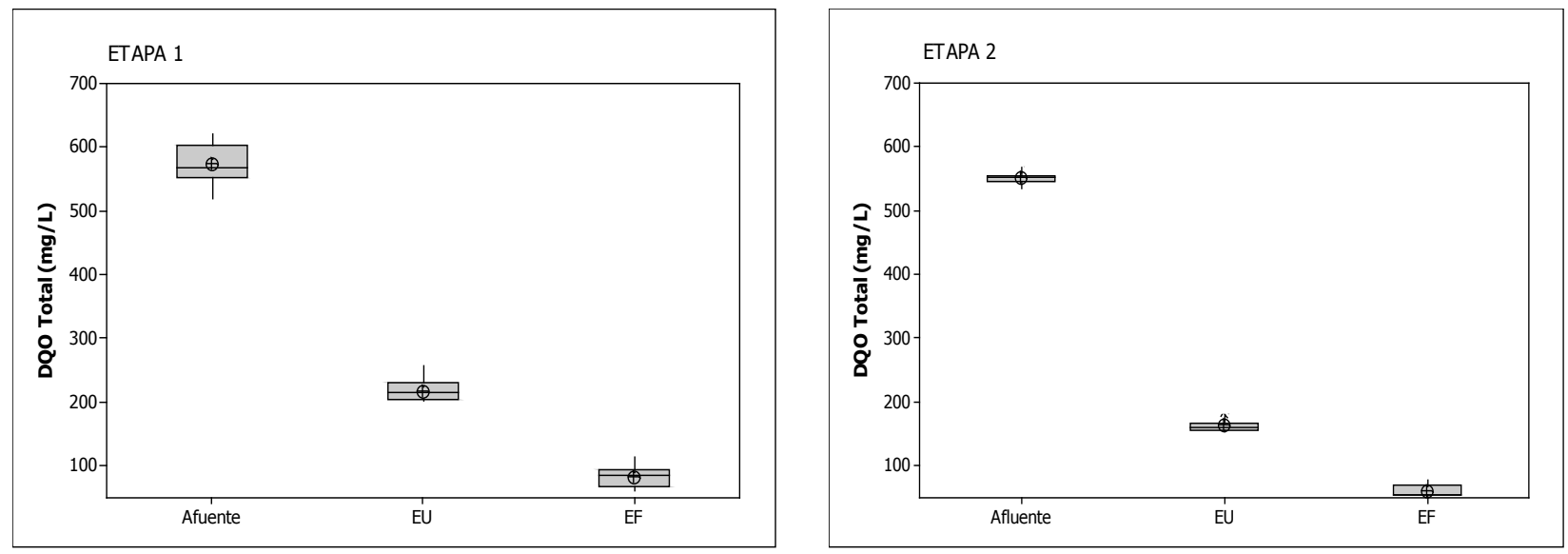

Figura 6 - Valores de DQQO total obtidos nas duas etapas de monitoramento dos reatores.

$O$ reator UASB teve menor desempenho na remoção de DQO total na etapa 1, com $60 \%$ de eficiência média operando com carga orgânica volumétrica de $1 \mathrm{kgDBO} 5 / \mathrm{m}^{3}$.dia. Na etapa 2, a eficiência média de remoção foi de $70 \%$, operando com a carga orgânica volumétrica de 1,5 kgDBO5/ $\mathrm{m}^{3}$.dia. Essa remoção está de acordo com a média esperada de $60 \%$ a $70 \%$ para reatores anaeróbios (CHERNICHARO, 2007). Constatou-se que, com o aumento da carga orgânica volumétrica do reator UASB na segunda etapa, houve maior remoção de matéria orgânica. De acordo com os parâmetros monitorados, $\mathrm{pH}$, alcalinidade total e AGVs, o reator UASB operou dentro das condições adequadas de funcionamento, possibilitando ao sistema boa eficiência na remoção de matéria orgânica e produção de metano. Observou-se que as cargas orgânicas aplicadas ao reator UASB nas duas etapas de monitoramento são favoráveis para remover matéria orgânica.

O filtro aeróbio produziu um efluente final com concentração média de DQQ total de 86 e 61 $\mathrm{mg} / \mathrm{L}$, respectivamente, nas etapas 1 e 2 . Portanto, a eficiência média de remoção de DQ total em todo o sistema foi de $85 \%$ na primeira etapa e $89 \%$ na segunda etapa.

Na Figura 7, apresenta-se o comportamento da DQO filtrada no afluente e efluente dos reato- 

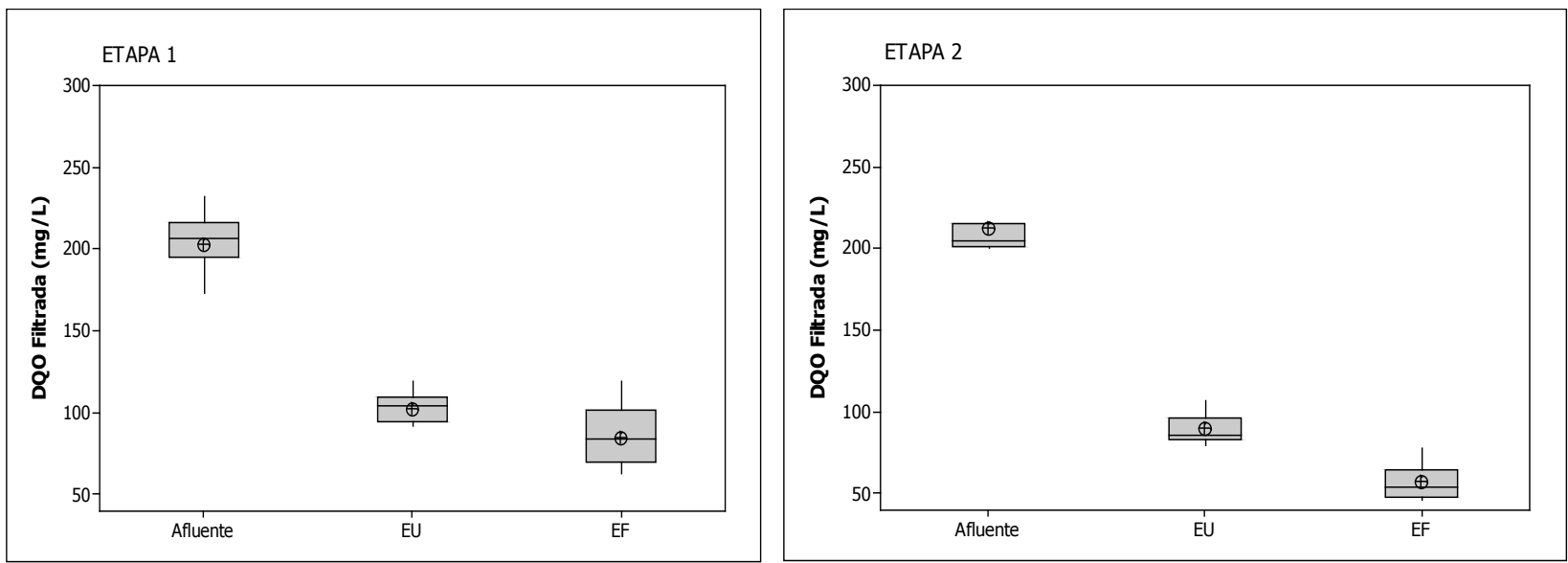

Figura 7 - Valores de DQQ filtrada obtidos nas duas etapas de monitoramento dos reatores.

res. Observa-se, por meio dos dados da Figura 7, que o valor médio do afluente foi de $207 \mathrm{mg} / \mathrm{L}$ na primeira etapa e $205 \mathrm{mg} / \mathrm{L}$ na segunda etapa. A eficiência média de remoção de DQ reator UASB foi de $50 \%$ na etapa 1 e $58 \%$ na etapa 2. A concentração média de DQO filtrada do efluente final foi de $84 \mathrm{mg} / \mathrm{L}$ (etapa 1) e $54 \mathrm{mg} / \mathrm{L}$ (etapa 2). Constatou-se, com os resultados apresentados, uma eficiência média de remoção de DQQ filtrada no sistema de $57 \%$ na primeira etapa e $73 \%$ na segunda etapa.

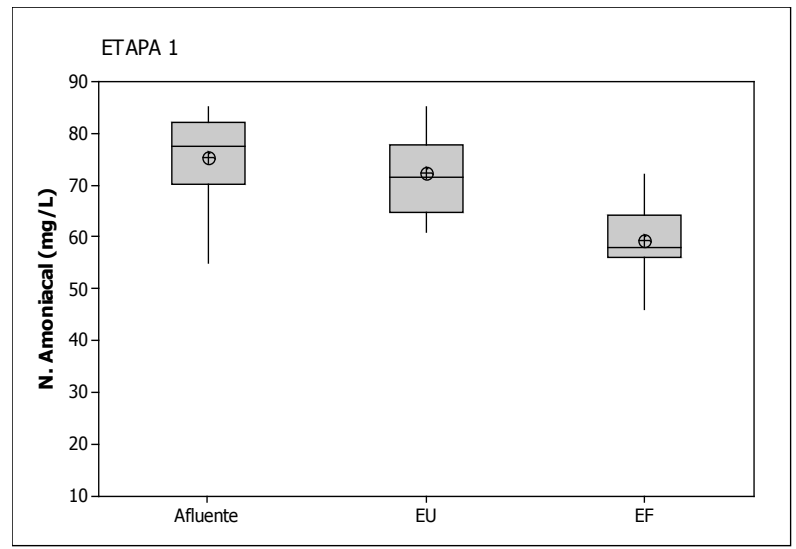

A eficiência média de remoção de DQQ filtrada foi menor que a remoção de DQQO total, indicando possivelmente que a maior parte da matéria orgânica removida do sistema está em suspensão ou é sedimentável.

A Figura 8 apresenta o comportamento do nitrogênio amoniacal no afluente e efluente dos reatores nas duas etapas de monitoramento do sistema experimental.

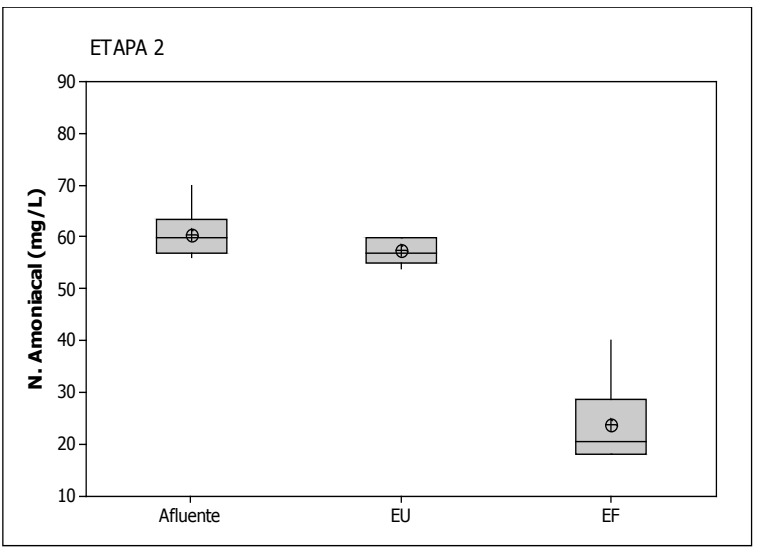

Figura 8 - Valores da concentração de nitrogênio amoniacal obtidos nas duas etapas de monitoramento dos reatores.

A concentração de nitrogênio amoniacal do afluente foi de $75 \mathrm{mgN}-\mathrm{NH} 4+/ \mathrm{L}$ e $61 \mathrm{mgN}-$ $\mathrm{NH} 4+/ L$ nas etapas 1 e 2 , respectivamente. No reator UASB, essa concentração aumentou em alguns dias de monitoramento, ou seja, não houve remoção de nitrogênio amoniacal devido à amonificação, resultando em um efluente com concentração média de $72 \mathrm{mg} / \mathrm{L}$ na etapa 1 e 57 $\mathrm{mg} / \mathrm{L}$ na etapa 2. 
A eficiência média de remoção de nitrogênio amoniacal no efluente do filtro aeróbio foi de $18 \%$ na etapa 1 e $58 \%$ na etapa 2, indicando que apenas na etapa 2 o processo de nitrificação foi eficiente.

A eficiência média de remoção de $\mathrm{N}-\mathrm{NH}_{4}+$ no sistema experimental foi de $21 \%$ na primeira etapa e $61 \%$ na segunda. $O$ efluente final apresentou concentração média de $\mathrm{N}-\mathrm{NH}_{4}+$ de $24 \mathrm{mgN}-\mathrm{NH}_{4}+/ \mathrm{L}$ na etapa mais eficiente (etapa 2). Apenas em alguns dias do monitoramento, a concentração de nitrogênio amoniacal apresentou valor mínimo de $18 \mathrm{mg} / \mathrm{L}$, atendendo aos padrões de lançamento proposto pela Resolução CONAMA 430/2011.

A concentração média de $\mathrm{N}-\mathrm{NO}_{2}-$ e $\mathrm{N}-\mathrm{NO}_{3}-$ foi de 2,5 e 10,4 mg/L, respectivamente, na primeira etapa. Na segunda etapa, a concentração média de $\mathrm{N}-\mathrm{NO}_{2}$ - foi de $0,9 \mathrm{mg} / \mathrm{L}$ e a de $\mathrm{N}-\mathrm{NO}_{3}-$, 32 $\mathrm{mg} / \mathrm{L}$. Constatou-se que a concentração de nitrato na etapa 1 foi baixa, além de mínima a conversão do nitrogênio amoniacal. $\mathrm{Na}$ etapa 2 , verificou-se maior concentração de nitrato, ou seja, ocorreu nitrificação e, consequentemente, houve maior conversão de nitrogênio.

\section{CONCLUSÕES}

Com os resultados obtidos, pode-se concluir que o tratamento conjugado de lixiviado de aterro sanitário com esgoto doméstico em reator UASB seguido de filtro aeróbio percolador constitui uma alternativa eficiente e viável para o tratamento de lixiviado, por favorecer seu tratamento por processo biológico.

Destaca-se que a COV aplicada ao reator UASB influenciou positivamente a remoção de material carbonáceo, expressa em termos de DBO5 e DQQO. A eficiência total do sistema experimental é destacada, obtendo remoções de DBO5 de $60 \%$ na primeira etapa e $76 \%$ na segunda, DQO total de $85 \%$ e $89 \%$ nas etapas 1 e 2 , respectivamente, DOQ filtrada de $57 \%$ (etapa 1) e $73 \%$ (etapa 2) e nitrogênio amoniacal de $21 \%$ na primeira etapa e $61 \%$ na etapa 2.

Para os indicadores de pH e DBO5, os valores médios do efluente final encontram-se dentro das condições padrões estabelecidas pela Resolução CONAMA 430/2011 para descarte em corpos aquáticos. Já o nitrogênio amoniacal apresentou valor médio próximo do padrão estabelecido pela norma citada, sendo que os valores mínimos chegaram a $18 \mathrm{mgN}-\mathrm{NH} 4+/ \mathrm{L}$.

\section{REFERÊNCIAS}

APHA - American Public Health Association Standard Methods for Examination of Water and Wastewater, 19. WASHINGTON: APHA, AWWA, WPCF, 2005.

ASASE, M. et al. Comparison of municipal solid waste management systems in Canada and Ghana: A case study of the cities of London, Ontario, and Kumasi, Ghana. Elsevier. Waste Management. p. 2779-2786, 2009.

BOHDZIEWICZ, JOLANTA; KWARCIAK, ANNA. The application of hybrid system UASB reactor-RO in landfill leachate treatment. Desalination. V.222 p. 128-134, 2008.

CHERNICHARO, C.A.L. Princípios do Tratamento Biológico de

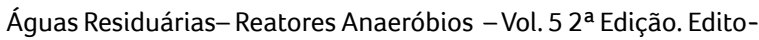
ra UFMG - Belo Horizonte, 308 p. 2007.

CONAMA. Conselho Nacional do Meio Ambiente. Resolução No 430 de 13 de maio de 2011.

IBGE - Instituto Brasileiro de Geografia e Estatística, Pesquisa Nacional de Saneamento Básico (2008), Rio de Janeiro, ISBN 978-85240-4135-8, 2010 b.

NGES, I. A.; LIU, J. Effects of anaerobic pré-treatment on the degradation of dewatered- sewage sludge. Renewable Energy. V. $34 \mathrm{p}$. 1795-1800, 2009.

ÖMAN, C. B.; JUNESTEDT, C. Chemical characterization of landfill leachates - 400 parameters and compounds. Waste Management[S.I.], v. 28, n. 10, p. 1876-1891, 2008

RENOU, S.; GIVAUDAN, J. G.; POULAIN, S.; DIRASSOUYAN, F.; MOULIN,P. Landfill leachate treatment: Review and opportunity. Journal of Hazardous Materials[S.I.], v. 150, n. 3, p. 468-493, 2008.

SANTOS, A. S. P. e JORDÃO, E. P. Pesquisa em escala de demonstração do tratamento combinado de lixiviado. DAE-SP, N 189 , pag. 26-39, 2012

VAN HAANDEL, A.; LETTINGA, G. Tratamento anaeróbio de esgoto em regiões de clima quente. Campina Grande - PB, 1994. 208p. 